\title{
Aspectos clínicos e histológicos da demodicose canina localizada e generalizada ${ }^{1}$
}

\author{
Naiani D. Gasparetto ${ }^{2 *}$, Kalinne S. Bezerra ${ }^{3}$, Luciana M.C. Soares ${ }^{3}$, Hérica Makino², \\ Anderson C.S. Oliveira ${ }^{4}$, Edson M. Colodel ${ }^{5}$, Arleana B.P.F. Almeida ${ }^{5}$ e Valéria R.F Sousa
}

\begin{abstract}
Gasparetto N.D., Bezerra K.S., Soares L.M.C., Makino H., Oliveira A.C.S., Colodel E.M., Almeida, A.B.P.F. \& Sousa V.R.F. 2018. [Clinical and histological aspects of localized and generalized canine demodicosis.] Aspectos clínicos e histológicos da demodicose canina localizada e generalizada. Pesquisa Veterinária Brasileira 38(3):496-501. Faculdade de Medicina Veterinária, Universidade Federal de Mato Grosso, Av. Fernando Corrêa da Costa 2367, Bairro Boa Esperança, Cuiabá, MT 78068-900, Brazil. E-mail: naianigasparetto@hotmail.com

Demodicosis is a skin condition caused by Demodex mite, frequently diagnosed in clinical routine. The purpose of this study was to compare the clinical and histological manifestations of localized and generalized demodicosis in dogs, relating the amount of mites and microscopic lesions. The study group was formed by 46 dogs, 28 with generalized demodicosis, and 18 with the localized form of the disease, all of them with positive skin scrapings. Macroscopic lesions data in dermatological form were noted, and skin samples were collected for microscopic study. The histopathological analysis was individually performed by three reviewers without intercommunication, being considered the result that more occurred. Alopecia, scaling, erythema, and crusting were the most common clinical lesions in both forms of the disease. Histological severe dermatitis occurred especially in dogs with localized and generalized disease that had concomitant pyoderma and Demodex sp. mites were visualized with intensity moderate and severe in the most dogs with both forms of the diseases. Perifolliculitis was the most evident microscopic follicular change in this study, followed by folliculitis and furunculosis wall, which had higher relative occurrence in dogs with localized demodicosis. According to the results obtained, the severity of histologic lesions does not necessarily correspond to the clinical presentation of the disease, in addition to the amount of mites that apparently is not indicative of localized or generalized clinical lesions, and cannot differentiate clinical disease by histopathology.
\end{abstract}

INDEX TERMS: Canine demodicosis, dermatology, dermatopathology, dogs, histology, parasitoses.

RESUMO.- Demodicose é uma afecção cutânea causada pelo ácaro Demodex sp. diagnosticada com frequência na rotina clínica veterinária. Objetivou-se descrever as manifestações

\footnotetext{
${ }^{1}$ Recebido em 26 de julho de 2016.

Aceito para publicação em 11 de janeiro de 2017

${ }^{2}$ Programa de Pós-Graduação em Ciências Veterinárias, Universidade Federal de Mato Grosso (UFMT), Av. Fernando Corrêa da Costa 2367, Bairro Boa Esperança, Cuiabá, MT 78060-900, Brasil. *Autor para correspondência: naianigasparetto@hotmail.com

${ }^{3}$ Residência Uniprofissional em Medicina Veterinária, Universidade Federal de Mato Grosso, Av. Fernando Corrêa da Costa 2367, Bairro Boa Esperança, Cuiabá, MT 78060-900.

${ }^{4}$ Departamento de Estatística, Instituto de Ciências Exatas e da Terra (ICET), Universidade Federal de Mato Grosso, Av. Fernando Corrêa da Costa 2367, Bairro Boa Esperança, Cuiabá, MT 78060-900.

${ }^{5}$ Faculdade de Medicina Veterinária (FAVET), Universidade Federal de Mato Grosso, Av. Fernando Corrêa da Costa 2367, Bairro Boa Esperança, Cuiabá, MT 78060-900.
}

clínicas e histológicas de cães com demodicose nas formas localizada e generalizada, relacionando a quantidade de ácaros e os achados microscópicos ao quadro clínico. Foram estudados 46 cães, sendo 28 com demodicose generalizada e $18 \mathrm{com}$ a forma localizada da doença, dos quais todos possuíam raspados de pele positivo. Destes caninos foram anotados dados de lesões macroscópicas em ficha dermatológica e coletaram-se amostras de pele para estudo microscópico. A análise histológica foi realizada por três avaliadores e os dados registrados sem comunicação entre os mesmos, sendo considerado o resultado que mais ocorreu. Alopecia, descamação, eritema e crostas foram lesões clínicas comuns às duas formas de apresentação da doença que mais ocorreram. Inflamação histológica dermal grave ocorreu especialmente nos cães com doença localizada e generalizada que possuíam piodermite concomitante e ácaros Demodex sp. foram visualizados com 
intensidade entre moderada e acentuada na maioria dos cães com ambas as formas da enfermidade. Perifoliculite foi a alteração folicular microscópica mais evidenciada nos caninos deste estudo, seguida por foliculite mural e furunculose que tiveram maior ocorrência relativa nos cães com demodicose localizada. De acordo com os resultados obtidos verificou-se que a gravidade das lesões histológicas não corresponde necessariamente à forma de apresentação clínica da enfermidade, além disso, a quantidade de ácaros não demonstrou ser indicativa de lesões clínicas localizadas ou generalizadas, bem como não é possível diferenciar a doença clínica através do exame histopatológico.

TERMOS DE INDEXAÇÃO: Demodicose canina, dermatologia, dermatohistopatologia, histologia, caninos, parasitoses.

\section{INTRODUÇÃO}

A demodicose canina foi descrita como a afecção mais comum na rotina clínica veterinária dermatológica, ocorrendo em 20,9\% dos casos assistidos em um Hospital Veterinário da região do estudo (Gasparetto et al. 2013). Esta dermatopatia é causada pela proliferação excessiva de ácaros comensais Demodex sp. que parasitam os folículos pilosos, glândulas sebáceas e sudoríparas apócrinas cutâneas, alimentando-se de células, se aprofundando no epitélio e induzindo a inflamação (Scott et al. 2001). As formas clínicas da demodicose são classificadas, de acordo com a extensão, em localizada (DL) e generalizada (DG). 0 curso é benigno na forma localizada e a maioria desses casos se resolvem espontaneamente. No entanto, a DG é a forma mais grave da doença e se apresenta como uma dermatite crônica com liquenificação, descamação, formação de crostas, hiperpigmentação, piodermite severa e alopecia, atingindo grandes áreas do corpo (Medleau \& Willemse 1995).

O diagnóstico da demodicose canina é estabelecido pela demonstração aumentada de formas adultas do ácaro ou por relação elevada de formas imaturas (ovos, larvas e ninfas) em relação aos adultos no raspado de pele profundo. Nas regiões periocular, perilabial ou interdigital, pode-se realizar tricogramas por epilação ou impressão com fita de acetato da área afetada para a visualização dos ácaros ao redor dos pelos (Gortel 2006, Pereira et al. 2012). 0 exame histológico e a detecção molecular por PCR (Polymerase Chain Reaction) são indicados naqueles casos em que existe suspeita, porém foram obtidos raspados negativos sucessivos ou em cães, como os da raça Sharpei, que tendem a ter folículos pilosos profundos e tortuosos que dificultam o acesso aos parasitos pelo método de raspagem (Scott et al. 2001).

No exame histológico da pele de um cão com demodicose pode ser evidenciado folículos contendo ácaros e restos de ceratinócitos, bem como perifoliculite, foliculite e furunculose supurativa ou granulomatosa (Gross et al. 2009). Ainda, as lesões microscópicas podem variar em função da presença e da extensão da infecção bacteriana secundária e se houver evolução para piodermite profunda. Lesões crônicas severas consistem de fibrose dérmica com obliteração de estruturas anexas (Hargis \& Ginn 2007), podendo ser observado com frequência sinais de hiperplasia da epiderme, evidenciada por hiperqueratose ortoqueratótica e queratose folicular.

Considerando os diferentes sinais clínicos da DL e DG em cães, duas hipóteses são levantadas: (i) os achados histológicos da pele dos cães com a doença localizada diferem daqueles com a forma generalizada devido a dissemelhança de gravidade. (ii) A quantidade de ácaros presente no tecido cutâneo define a gravidade da doença clínica. Sendo assim, um detalhamento comparado no que se refere às alterações clínicas e histológicas de caninos com demodicose nas formas localizada e generalizada torna-se fundamental para a compreensão da patogenia em suas diferentes formas de apresentação. 0 objetivo deste estudo foi descrever as características histológicas de caninos com DL e DG e avaliar a relação com as características clínicas observadas nestes cães.

\section{MATERIAL E MÉTODOS}

Neste estudo foram incluídos cães atendidos no Hospital Veterinário da Universidade Federal de Mato Grosso (UFMT) com sinais clínicos dermatológicos que na avaliação microscópica do raspado profundo de pele foram observados ácaros Demodex sp. Para a coleta de espécimes clínicos e a publicação dos resultados obtidos todos os proprietários assinaram um termo de consentimento. Os procedimentos desenvolvidos neste trabalho foram submetidos ao Comitê de Ética no Uso de Animais-CEUA/UFMT e aprovados sob o número 23108.018821/14-7.

Dados de anamnese e do exame físico foram registrados em ficha dermatológica a fim de avaliar a ocorrência e distribuição dos sinais clínicos. Demodicose generalizada foi considerada em cães com cinco ou mais lesões ou com comprometimento de uma área extensa do corpo e naqueles com até quatro lesões, pequenas e delimitadas, considerou-se demodicose localizada (Scott et al. 2001). Na biopsia, os fragmentos de pele foram obtidos utilizando "punch" 3mm (Gasparetto et al. 2013), após anestesia local subcutânea com Lidocaína $2 \%$ e os mesmos foram fixados em solução de formalina tamponada a $10 \%$. As amostras foram processadas rotineiramente, incluídas em parafina, cortadas a $5 \mu \mathrm{m}$ de espessura e coradas pela hematoxilina-eosina (HE) (Prophet et al. 1992).

A análise histológica foi realizada por três avaliadores e as alterações observadas referentes à epiderme, derme, folículos pilosos, glândulas sebáceas, exsudatos e presença do ácaro, foram anotadas em ficha histológica padrão sem que houvesse comunicação entre os mesmos. Os dados foram revisados e as intensidades, quando presentes, agrupadas (discreto/leve e moderado/acentuado), prevalecendo o resultado de maior concordância entre os três. Utilizou-se para a análise dos dados obtidos a estatística descritiva e os testes Qui-quadrado e Exato de Fischer para os dados qualitativos, sendo considerados estatisticamente significantes os valores de $\mathrm{p} \leq 0,05$.

\section{RESULTADOS}

Um total de 46 cães, sendo 24 machos (52,2\%/DL=9, DG=15) e 22 fêmeas $(47,8 \% / D L=9, D G=13)$, foram diagnosticados com demodicose durante o período do estudo, sendo 23 meses a idade média com variação entre 2 e 156 meses (Moda=6 meses, Mediana=9 meses). A maioria dos cães era de raça pura $(n=31 ; 67,4 \%)$ e 32,6\% dos cães não possuíam raça definida. Dentre as raças incluíram York Shire e Pit Bull $(n=5)$, Poodle $(n=4)$, Pinscher $(n=3)$, Rottweiler, Shih Tzu, Lhasa Apso, Bulldog Inglês e Boxer ( $n=2)$; Pequinês, Dálmata, Teckel e Bull Terrier ( $\mathrm{n}=1)$.

Demodicose generalizada foi a forma da doença mais observada, ocorrendo em 28 cães (60,9\%) e 39,1\% (18) dos caninos apresentaram a forma localizada da enfermidade. Alopecia (44/95,6\%), descamação (37/80,4\%), eritema $(34 / 73,9 \%)$ e crostas $(33 / 71,7 \%)$ foram as alterações 
dermatológicas de maior relevância (Fig.1), além de pápulas (27/58,7\%), pústulas (23/50\%) e hiperpigmentação (17/36,9\%) que também ocorreram (Fig.1). Relatou-se que $54,3 \%$ dos cães tinham prurido em intensidades variáveis. Piodermite ocorreu em 22 caninos, sendo 95,5\% correspondente a cães com demodicose generalizada. Os aspectos clínicos dos cães deste estudo estão demonstrados no Quadro 1.

Referente às características do exame histopatológico, hiperqueratose ortoqueratótica foi a reação epidérmica mais frequente $(65,2 \%)$ nos cães com demodicose deste estudo, no entanto, acantose $(41,3 \%)$ e acantólise $(4,3 \%)$ também ocorreram, concomitantes ou não, de maneira reduzida.
Na derme, apenas dois cães $(4,3 \%)$ não demonstraram processos inflamatórios, de forma que nos cães com inflamação dermal, exsudato predominantemente linfoplasmocitário foi o de maior ocorrência $(n=22 ; 47,8 \%)$, seguido pelo exsudato linfohistioplasmocitário e neutrofílico ( $\mathrm{n}=21 ; 45,6 \%)$ e apenas um caso com infiltrado inflamatório neutrofílico $(2,2 \%)$. Intensidade variável de seções de artrópodes de exoesqueleto quitinoso com parede delgada e eosinofílica, contendo segmentos pontuais basofílicos no interior, de morfologia compatível com Demodex sp. puderam ser observados preenchendo e expandindo o lúmen de folículos pilosos de 39 cães $(84,8 \%)$. Os achados morfológicos frequentes foram

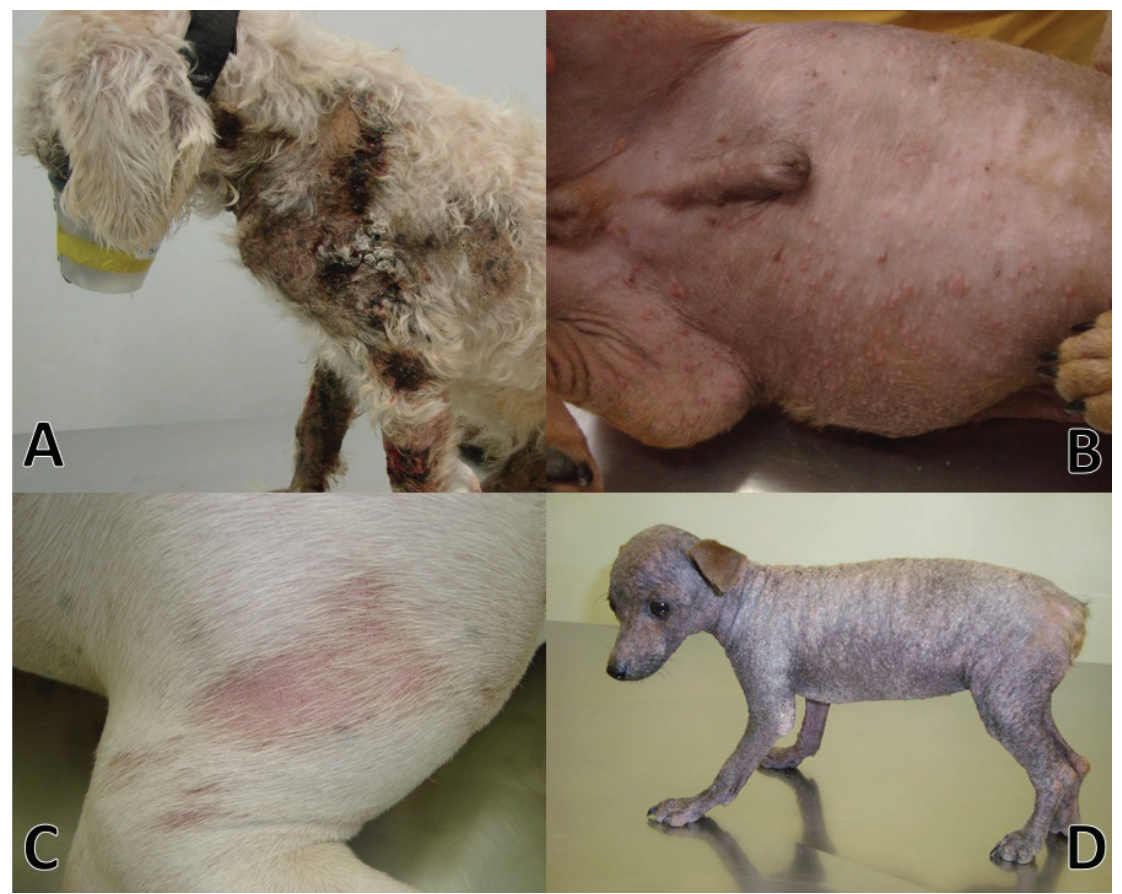

Fig.1. Aspectos clínicos em caninos com demodicose . (A) Canino macho, 8 anos, com demodicose generalizada, apresentando lesões crostosas na região escapular e em membros anteriores. (B) Canino macho, 6 meses, com demodicose generalizada, apresentando pápulas e pústulas na região ventral. (C) Canino fêmea, 1 ano, com demodicose localizada, apresentando alopecia e eritema na região escapular direita. (D) Canino fêmea, 4 meses, com demodicose generalizada, apresentando alopecia total, descamação e hiperpigmentação.

Quadro 1. Lesões evidenciadas no exame físico dermatológico de 46 cães com demodicose localizada e generalizada

\begin{tabular}{lccc}
\hline \multicolumn{1}{c}{ Alteração dermatológica } & $\begin{array}{c}\text { Demodicose } \\
\text { localizada n (\%) }\end{array}$ & Demodicose generalizada n (\%) & $\begin{array}{c}\text { Total } \\
\mathrm{n}(\%)\end{array}$ \\
\hline Alopecia & $17(94,4)$ & $27(96,4)$ & $44(95,6)$ \\
Descamação & $11(61,1)$ & $26(92,8)$ & $37(80,4)$ \\
Eritema & $10(55,5)$ & $24(85,7)$ & $34(73,9)$ \\
Crostas & $10(55,5)$ & $23(82,1)$ & $33(71,7)$ \\
Pápulas & $5(27,8)$ & $22(78,6)$ & $27(58,7)$ \\
Pústulas & $2(11,1)$ & $21(75)$ & $23(50)$ \\
Piodermatite & $1(5,5)$ & $21(75)$ & $22(47,8)$ \\
Hiperpigmentação & $4(22,2)$ & $13(46,4)$ & $17(36,9)$ \\
Urticas & $2(11,1)$ & $8(28,6)$ & $10(21,7)$ \\
Úlceras/Erosões & 0 & $7(25)$ & $7(15,2)$ \\
Cilindros foliculares & $1(5,5)$ & $4(14,3)$ & $5(10,9)$ \\
Total de cães & $18(39,1)$ & $28(60,9)$ & $46(100)$
\end{tabular}


dilatação ou hiperqueratose folicular, além de infiltrado inflamatório linfohistioplasmocitário e difuso em região perifolicular $(58,7 \%)$ ou infiltrado no epitélio folicular, onde se observou degeneração hidrópica e necrose celular individual das células epiteliais foliculares caracterizando foliculite mural $(23,9 \%)$. Raramente se observou ruptura folicular caracterizando furunculose $(21,7 \%)$ (Fig.2). Tais alterações foliculares ocorreram de forma coexistente ou não. Inflamação de glândulas sebáceas foi descrita em 16
$(34,8 \%)$ caninos e destes, $81,2 \%$ apresentaram infiltrado inflamatório linfohistioplasmocitário e em dois $(12,5 \%)$ e um $(6,3 \%)$ ocorreram exsudato linfohistioplasmocitário e neutrofílico; e neutrofílico, respectivamente. Não foram visualizados ácaros Demodex sp. parasitando glândulas sebáceas dos animais deste estudo.

Os dados histológicos observados na pele dos cães com demodicose nas formas localizada e generalizada estão descritos no Quadro 2.

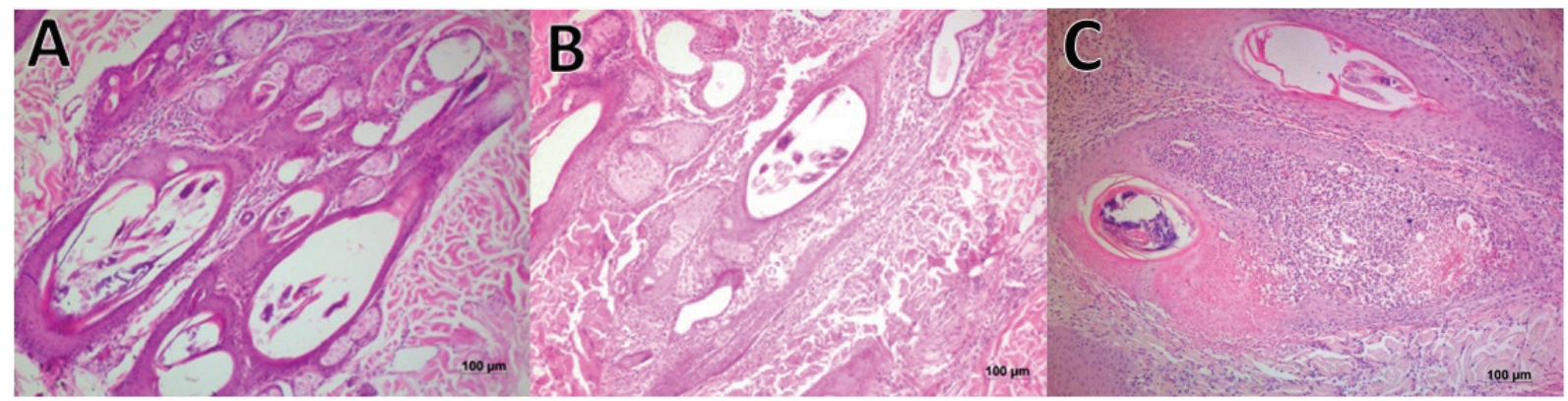

Fig.2. Padrões histopatológicos foliculares de caninos com demodicose. (A) Perifoliculite. (B) Foliculite Mural. (C) Furunculose. HE, obj.10x.

Quadro 2. Alterações dermatohistopatológicas descritas em 46 cães com demodicose localizada e generalizada

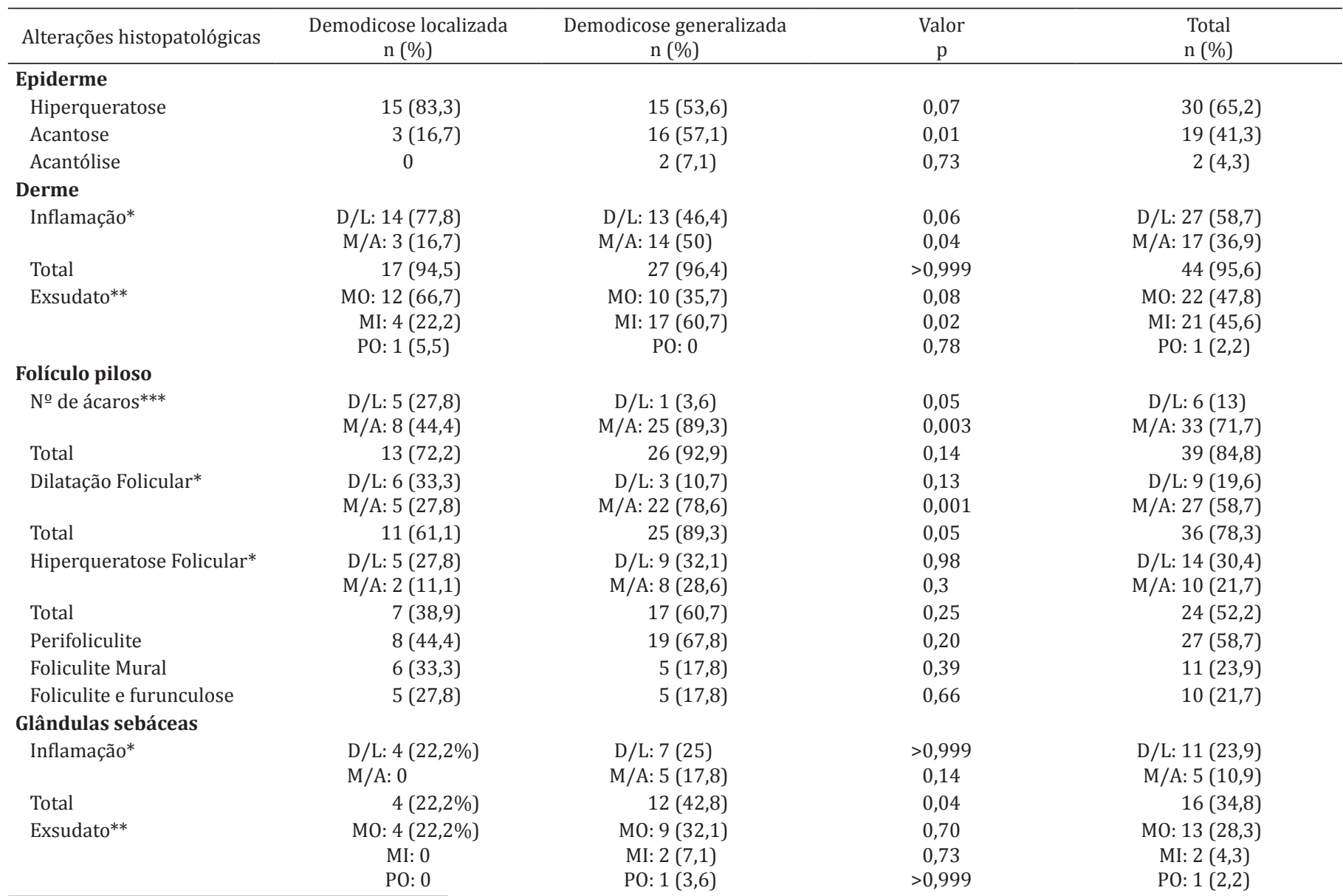

$* \mathrm{D} / \mathrm{L}=$ discreto/leve, ${ }^{* *} \mathrm{MO}=$ mononuclear, ${ }^{* *}{ }^{*} \mathrm{D} / \mathrm{L}=1$ a 2 ácaros por folículo piloso em média; $\mathrm{M} / \mathrm{A}=$ moderado/acentuado, $\mathrm{MI}=$ misto, $\mathrm{PO}=$ polimorfonuclear, $\mathrm{MO}=$ acima de 3 ácaros por folículo piloso em média. 


\section{DISCUSSÃO}

Este estudo comparou as manifestações clínicas e os achados histológicos de cães com DL e DG. Não foi detectada preferência das formas clínicas em relação ao sexo. Este achado está de acordo com os descritos no que se refere à similaridade da proporção entre machos e fêmeas em relação às lesões nas formas localizada e generalizada (Muller et al. 2001, Villalobos 2011). Os achados de Moda e Mediana referente às idades dos caninos concordam com os descritos para cães com a doença localizada já que esta forma desenvolve-se com maior frequência em cães jovens (Muller et al. 2001, Santarem 2007), no entanto, cinco cães com idade igual ou acima da média de dois anos demonstraram lesões brandas. Dezesseis cães com doença generalizada apresentaram menos de 24 meses e apesar de a maioria dos casos de doença na forma mais grave ocorrer em cães entre dois e cinco anos de idade muitos casos se inicia na fase infantil e se não houver resolução espontânea das lesões ou o paciente não receber tratamento adequado podem evoluir para o quadro generalizado (Scott et al. 2001). Os cães com raça definida foram os mais acometidos já que estes animais tendem a ter predisposição hereditária para desenvolver a doença, o que parece apoiar-se num modelo autossômico recessivo de transmissão genética (Muller et al. 2001).

A doença generalizada foi a forma clínica mais frequente. Sabe-se que a demodicose decorre de um defeito do sistema imunológico que viabiliza a multiplicação exacerbada desses ácaros nos animais, induzindo à forma clínica mais grave da enfermidade (Delayte et al. 2006). Alopecia, descamação, eritema e crostas manifestam-se pela ação do ácaro e sua alimentação a base de restos celulares no folículo piloso. Estes sinais clínicos correspondem às lesões iniciais e devido a este fato culminam em ocorrência elevada aos casos de demodicose nas formas localizada e generalizada, como evidenciado neste estudo (Scott et al. 2001). Pústulas, piodermites, úlceras/erosões foram afecções de maior ocorrência nos casos de doença na forma generalizada no qual propicia ambiente cutâneo ecológico e imunologicamente favorável para a colonização de maneira extrema (Caswell et al. 1997, Muller et al. 2001, Gross et al. 2009) induzindo, na maior parte dos casos, evolução para piodermite como observado neste estudo. A piodermite decorre da proliferação de microorganismos oportunistas, como Staphylococus pseudintermedius e Pseudomonas spp. (Wilkinson \& Harvey 1998, Herni et al. 2006) e quando presente pode causar prurido, odor desagradável, linfadenopatia, febre, anorexia e letargia (Quinn et al. 1997, Medleau \& Hnilica 2003).

Pouco mais da metade $(54,3 \%)$ dos proprietários relataram prurido em seus cães, sinal relacionado à piodermite bacteriana e à reação imunológica contra o ácaro Demodex sp. que se localiza no interior do folículo piloso promovendo a ação linfocitária contra os ceratinócitos portadores de antígenos próprios alterados ou até mesmo de antígenos do próprio ácaro (Caswell et al. 1997, Hargis \& Ginn 2007).

Com relação às alterações histológicas, a hiperqueratose corresponde à resposta precoce e inespecífica a uma determinada injúria e possivelmente devido a este fato a alteração da epiderme foi mais frequente nos cães deste estudo, em ambas as formas de apresentação da doença (Baker 1969). Plasmócitos, linfócitos, macrófagos e mastócitos infiltrados no epitélio dermal é um achado consistente nos casos de demodicose (Scott et al. 2001, Gross et al. 2009) sendo compatíveis com o exsudato linfohistioplasmocitário, discreto a leve, intersticial e perivascular, presente na maioria dos cães estudados com a doença na forma localizada. Daqueles cães com demodicose generalizada, 60,7\% demonstraram inflamação linfohistioplasmocitária associada a infiltrado neutrofílico, indicando presença de piodermite, condição frequente nesses casos. Em todos os casos foram observados mastócitos com intensidade variada. Ainda, inflamação dermal com intensidade entre discreta e leve é esperada nos casos de doença na forma localizada como visualizado neste estudo, no entanto, $46,4 \%$ dos cães com doença generalizada demonstraram na derme esta mesma intensidade de inflamação. Este elevado índice de cães com DG demonstrando inflamação dermal discreta e leve contesta a hipótese de que as alterações histológicas diferem entre as duas formas clínicas da doença, evidenciando que a manifestação clínica severa produzirá inflamação microscópica dermal massiva, circunstancialmente em casos com piodermite associada, tendo em vista que todos os caninos $(17 ; 36,9 \%)$ com inflamação dermal entre moderada e acentuada apresentaram pústulas e dermatite úmida ao exame clínico.

Hiperqueratose folicular e inflamação de glândulas sudoríparas e sebáceas predominantemente mononuclear apontam casos crônicos e ocorreram em maior quantidade nos cães com doença generalizada (Hargis \& Ginn 2007, Gross et al. 2009). Estes resultados concordam em termos de cronicidade já que a demodicose generalizada é descrita como recidivante ou decorrente da evolução de doença localizada não curada (Scott et al. 2001).

A visualização de Demodex sp. no interior dos folículos pilosos em 84,8\% dos cães deste estudo justifica as alterações inflamatórias foliculares e coexistências. Além disso, a maior ocorrência com intensidade de indivíduos entre moderada e acentuada $(71,7 \%)$ para ambas as formas (DL e DG) demonstra que a clínica da doença não se determina pela parasitemia e pode ser regulada diretamente pela resposta imune do hospedeiro (Tizard 2002). Naqueles caninos que não foi possível a identificação do ácaro, pode-se frequentemente observar discreto infiltrado inflamatório com distribuição multifocal na região perifolicular, composto por linfócitos, plasmócitos e macrófagos, normalmente associados a alterações epidérmicas como discreto espessamento ou hiperqueratose ortoqueratótica e discreta dermatite composta por infiltrado linfoplasmocitário próximo a vasos sanguíneos, indicando que tal ausência pode estar relacionada à região do local de biopsia e/ou ao tamanho da amostra coletada já que todos foram positivos ao raspado de pele.

Perifoliculite foi a alteração morfológica que mais ocorreu nos caninos deste estudo. Caracterizada como estágio inicial do processo inflamatório, ocorre pela presença de macrófagos e linfócitos ao redor do folículo piloso evidenciando reação do organismo ao agente agressor, apesar deste estar comumente no interior do folículo, local onde normalmente não ocorre resposta inflamatória (Scott et al. 2001). 0 fato de ter sido evidenciada tanto em cães com a doença localizada como naqueles com lesões clínicas mais graves denota não só a resposta imune local aparentemente eficiente da perifoliculite, mas também exacerbada devido ao quadro clínico que ela origina.

Como evolução da inflamação, foliculite mural pode ser observada decorrente da infiltração de linfócitos e histiócitos na parede dos folículos ocasionando injúria aos ceratinócitos 
foliculares (Caswell et al. 1997, Hargis \& Ginn 2007). Em um estudo retrospectivo, a foliculite mural foi um achado comum a todos os cães com sinais clínicos da enfermidade, demonstrando ser o estágio de inflamação mais visualizado nos casos de demodicose (Caswell et al. 1995). Proporcionalmente, mais casos de foliculite mural foram observados em cães com a doença localizada neste estudo e este fato descaracteriza a afirmação de que cães com apresentação clínica leve demonstram lesões histológicas em estágio precoce. Dilatação folicular foi visualizada em 36 caninos deste estudo e este acúmulo de Demodex sp. no interior dos folículos pilosos podem levar a ruptura e liberação dos ácaros no interstício dermal, os quais são envolvidos por extensa inflamação purulenta ou piogranulomatosa caracterizada por furunculose (Gross et al. 2009). Observou-se furunculose piogranulomatosa multifocal em dez cães deste estudo (DL 27,8\%; DG 17,8\%) sendo ainda, de forma relativa, os cães com a doença localizada os mais acometidos reafirmando que os estágios histológicos de inflamação folicular podem possuir gravidade semelhante a ambas as formas clínicas da enfermidade.

\section{CONCLUSÕES}

Os resultados deste estudo demonstraram que alopecia, descamação, eritema e crostas são sinais clínicos comuns aos cães com demodicose nos casos brandos e severos.

A quantidade de ácaros visualizados ao exame histológico não indica inter-relação com a ocorrência de lesões clínicas localizadas ou generalizadas.

Não é possível diferenciar doença clínica localizada e generalizada através do exame histológico, sendo a piodermite fator desencadeante da inflamação microscópica dermal grave em ambas as formas clínicas de demodicose.

A gravidade da doença parece estar mais relacionada à deficiência na resposta imune por parte do hospedeiro que com a parasitemia.

Agradecimentos.- Aos residentes do setor de dermatologia do Hospital Veterinário da UFMT pelo encaminhamento dos cães com demodicose.

\section{REFERÊNCIAS}

Baker K.P. 1969. The histopathology and pathogenesis of demodecosis of the dog. J. Comp. Pathol. 79(3):321-327. http://dx.doi.org/10.1016/00219975(69)90045-0. PMid:5348108.

Caswell J.L., Yager J.A., Ferrer L. \& Weir J.A.M. 1995. Canine demodicosis: a re-examination of the histopathologic lesions and description of the immunophenotype of infiltrating cells. Vet. Dermatol. 6(1):9-19. http:// dx.doi.org/10.1111/j.1365-3164.1995.tb00035.x.

Caswell J.L., Yager J.A., Parker W.M. \& Moore P.F. 1997. A propective study of the immunophenotype and temporal changes in the histologic lesions of canine demodicosis. Vet. Pathol. 34(4):279-287. http://dx.doi. org /10.1177/030098589703400403. PMid:9240836.
Delayte E.H., Otsuka M., Larsson C.E. \& Castro R.C.C. 2006. Eficácia das lactonas macrocíclicas sistêmicas (ivermectina e moxidectina) na terapia da demodicidose canina generalizada. Arq. Bras. Med. Vet. Zootec. 58(1):3138. http://dx.doi.org/10.1590/S0102-09352006000100006.

Gasparetto N.D., Trevisan Y.P.A., Almeida N.B., Neves R.C.S.M., Almeida A.B.P.F, Dutra V., Colodel E.M. \& Sousa V.R.F. 2013. Prevalência das doenças de pele não neoplásicas em cães no município de Cuiabá, Mato Grosso. Pesq. Vet. Bras. 33(3):359-362. http://dx.doi.org/10.1590/S0100-736X2013000300014.

Gortel K. 2006. Update on canine demodicosis. Vet. Clin. North Am. Small Anim. Pract. 36(1):229-241. http://dx.doi.org/10.1016/j.cvsm.2005.09.003. PMid:16364787.

Gross T.L., Ihrke P.J., Walder E.J. \& Affolter V.K. 2009. Doenças de Pele do Cão e do Gato: diagnóstico clínico e histopatológico. $2^{\mathrm{a}}$ ed. Roca, São Paulo. 904p.

Hargis A.M. \& Ginn P.E. 2007. The integument, p.1107-1261. In: McGavin M.D. \& Zacchary J.F. (Eds), Pathologic Basis of Veterinary Disease. 4th ed. Mosby, St Louis.

Herni J.A., Boucher J.F., Skogerboe T.L., Tarnacki S., Gajewski K.D. \& Lindeman C.J. 2006. Comparison of efficacy of cefpodoxime proxetil and cephalexin in treating bacterial pyoderma in dogs. Int. J. Appl. Res. Vet. Med. 4:85-93

Medleau L. \& Hnilica K.A. 2003. Dermatites parasitárias, p.59-88. In: Medleau L., Hnilica K.A. (Eds), Dermatologia de Pequenos Animais. Roca, São Paulo.

Medleau L. \& Willemse T. 1995. Efficacy of daily amitraz therapy for refractory, generalized demodicosis in dogs: two independent studies. J. Am. Anim. Hosp. Assoc. 31(3):246-249. http://dx.doi.org/10.5326/15473317-313-246. PMid:7634060.

Muller G.H., Kirk R.W. \& Scott D.W. 2001. Parasitic skin diseases, p.457-474. In: Ibid. (Eds), Muller \& Kirk's Small Animal Dermatology. 6th ed. W.B. Saunders, Philadelphia, PA.

Pereira A.V., Pereira S.A., Gremião I.D.F., Campos M.P. \& Ferreira A.M.R. 2012 Comparison of acetate tape impression with squeezing versus skin scraping for the diagnosis of canine demodicosis. Aust. Vet. J. 90(11):448-450. http://dx.doi.org/10.1111/j.1751-0813.2012.00994.x. PMid:23106326.

Prophet E.B., Mills B., Arrington J.B. \& Sobin L.H. 1992. Laboratory methods in histotechnology. American Registry of Pathology, Armed Forces Institute of Pathology, Washington, DC. 279p

Quinn P.J., Donnely W.J.C., Carter M.E., Markey B.K.J., Torgenson P.R. \& Breathnach R.M.S. 1997. Microbial and Parasitc Diseases of the Dog and Cat. W.B. Saunders, London. 362p.

Santarem V. 2007. Demodicose canina: revisão. Clin. Vet. 69:86-96.

Scott D.W., Miller W.H. \& Griffin C.E. 2001. Doenças parasitárias da pele, p.423427. In: Ibid. (Eds), Muller e Kirk, Dermatologia de Pequenos Animais. $6^{a}$ ed. Interlivros Edições Ltda, Rio de Janeiro. 1130p.

Tizard I.R. 2002. Imunologia Veterinária, uma introdução. 6ª ed. Roca, São Paulo. 404p.

Villalobos W.O.R. 2011. Estudio de la prevalencia de la parasitación por Demodex spp. en el perro mediante una técnica de PCR en tiempo real, Barcelona. Máster oficial de Investigación en Veterinaria, Universidad Autónoma de Barcelona.

Wilkinson G.T. \& Harvey R.G. 1998. Doença parasitária: demodicose, p.7379. In: Ibid. (Eds), Atlas Colorido de Dermatologia dos Pequenos Animais: guia para o diagnóstico. $2^{\mathfrak{a} \text { e }}$ ed. Manole, São Paulo. 